\section{rev Psi}

Revista de Psicología (UNLP)

https://revistas.unlp.edu.ar/revpsi

\title{
Hacia una "psicología andina" para la liberación
}

\author{
Mirta Videla1,2 \\ Correspondencia \\ mirtavidela40@gmail.com \\ Filiaciones institucionales \\ ${ }^{1}$ Facultad de Psicología, Universidad de Buenos $\quad{ }^{2}$ Colectivo profesional PSICOANDINAS \\ Aires (Argentina) \\ (Argentina)
}

\section{Resumen}

El presente artículo es una crítica al modelo hegemónico de formación y ejercicio profesional imperante en psicológica sudamericana. Propone abrir lo académico al calor de las sabidurías de la cosmovisión andina, borrada por la colonización, como nueva forma de construcción espiritual del conocimiento. Ello permitirá corazonar la ciencia comprometiéndola con la vida, sumar a ella una nueva dimensión afectivoemocional, y construir formas distintas de conocimiento para sembrar horizontes diferentes de civilización y de existencia.

\section{Palabras clave}

egofrenia $\mid$ memoricidio $\mid$ cosmovisión andina $\mid$ sentipensar | corazonar

\section{Licencia}

(c) Copyright: Videla, M. Este trabajo se distribuye bajo una licencia de Cultura Libre CC-BY 4.0

\section{Entidad editora}

RevPsi es una publicación de la

Facultad de Psicología (Universidad

Nacional de La Plata, Argentina)

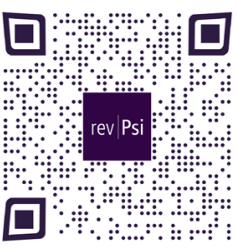

ACCESO ABIERTO DIAMANTE 


\section{Para uma "psicología andina" para a libertacão}

\section{Resumo}

Este artigo é uma crítica ao modelo hegemônico de formação e prática profissional vigente na psicologia sul-americana. Propõe abrir a academia à sabedoria da cosmovisão andina, apagada pela colonização, como uma nova forma de construção espiritual do conhecimento. Essa abertura nos permitiria centrar a ciência, comprometê-la com a vida e acrescentar outras formas de conhecimento a ela, a fim de semear novos horizontes de civilização e existência.

\section{Palavras-chave}

egofrenia | memoricídio | visão de mundo andina | sentir-pensar | coracão

\section{Towards an 'Andean psychology' for liberation}

\section{Abstract}

This article is a critique of the hegemonic model of training and professional practice prevailing in South American psychology. It proposes to open academia to the wisdom of the Andean worldview, erased by colonisation, as a new form of spiritual construction of knowledge. This openness would allow us to heart science, to commit it to life, and to add other forms of knowledge to it, in order to sow new horizons of civilisation and existence.

\section{Keywords}

egofrenia | memorycide | Andean cosmovision | feel-think | hearting 


\section{Aspectos destacados del trabajo}

- Se propone una perspectiva alternativa para la concepción teórica y práctica de la psicología actual.

- Esta perspectiva considera conocimientos y aspectos clave de la cultura comunitaria andina.

- Se muestran los vínculos entre esta propuesta y un posible camino para la liberación.

- Se incluyen reflexiones sobre la construcción de conocimientos en las ciencias y en la psicología en particular.

Para mis colegas:

Alicia Torres Sachi, Julia Salim, Carolina Alvarez, Carolina Wajnerman, Analía Sofía Zelaya, Fernanda Cieza, María Laura Lerma, Eliana Inés Panozo, Bibiana Anton, Alejandra Carrizo, Irma Lidia Silva, Martina Agudo Pelaytay.

He redefinido el titulo después de pensar mucho acerca de si existiría una psicología andina o si la psicología es una sola, aplicable en diferentes áreas del comportamiento humano psico-social. Quizá por mis ganas de integrar y no fracturar ya nada más de lo que padecemos, me inclino por lo segundo, sujeto a lo que opinen todas.

Antes que nada me inclino y les propongo pertenecer a un "continente sudamericano" y dejar de lado etiquetas descartables de "latinoamericano" o "iberoamericano", producto del pensamiento colonizador.

Mi propuesta se inclina por una "psicología visceral", con la imagen de hacer "desde las entrañas", frente a tanto abuso actual de "cerebrosidades" y "neuroexpertos", con abundancia de modelos y formulas enlatadas de cómo vivir, amar, enfermar, sanar y morir. Como escribió el maestro indio jujeño Osvaldo Maidana: "En los últimos tiempos se han multiplicado nuevos sacerdotes que se llaman antropólogos, psicólogos, abogados, médicos, economistas y científicos, dueños de la verdad y la sabiduría y que fundan imperios. Porque los imperialismos no son exclusivamente políticos sino que pueden ser religiosos, científicos y económicos. Y sus nuevas armas son el cinismo, la burla, la desvergüenza" (Maidana, 1997).

Por eso me siento mejor hablando como una psicóloga de Los Andes, con nuestro referente femenino regional que apela a la tierra madre de la cordillera andina, esa donde nací, crecí y permaneceré.

He consultado muchos libros estos últimos tiempos, también información que me enviaron generosamente algunos colegas. Tuve charlas con amigas andinas, hecho 
importante, como además con integrantes de mi familia criolla andina, en una ceremonia de profundo respeto y homenaje para quienes en este continente hace siglos ya sabían como curar, aliviar y proteger la salud integral de las personas y sus comunidades.

Intenté una breve aproximación en estos temas, para poder desarrollarlo ampliado. No es una propuesta teórica ni técnica, sino solamente el equivalente a un fuerte abrazo para todas, todos, que llegue a trasmitir mi deseo de una psicología capaz de apapachar, ternurar, corazonar, amar y mimar entre nosotras, nosotros y con los demas.

Se trata de una estrategia protectora de la salud mental, basada en el total respeto y reconocimiento por el saber de nuestros abuelos, de los que provenimos. Solo así haremos posible el proceso de descolonizar nuestro pensamiento, el poder, el saber y el ser que nos ayude para juntarnos más, sin grietas ni fracturas que despedacen aún más nuestra esencia andina.

Espero que llegue a constituirse en estimulo para la creación de todas, todos, y continuidad para quienes ya poseen valiosas obras al respecto. Siento que padecemos heridas de siglos y se hace necesaria una clínica nacional, para romper con la "egofrenia" y lograr sentir - con - otros, juntarnos como abrazando un valle, como rodeando un cerro. Por eso mi propuesta es sumarnos para reflexionar y enfrentar al monstruo que nos devora: violencia y crueldad, competencias profesionales feroces, necesidad de lucimientos personales narcisistas, negación de la alteridad, desprecio por lo ajeno, enajenaciones políticas y religiosas fundamentalistas, como también el borramiento de las formas y costumbres de nuestro antepasados andinos, de lo que aún podemos aprender mucho y sabemos poco o nada.

Las comunidades andinas poseían acabados conocimientos sobre como curar, sanar y proteger la salud. También una cosmovisión sobrenatural de la locura y múltiples formas ancestrales de terapias utilizadas. La enfermedad mental fue considerada como consecuencia del accionar mágico de seres maléficos o benéficos, como castigo o venganza por faltas cometidas. No muy lejos de los sentimientos de culpa inconsciente descriptos por el psicoanálisis y del credo católico culpabilizante. Lo importante a destacar es que todo diagnóstico y tratamiento era siempre realizado por familia, en grupos y comunidades. Jamás de forma individual. Celebraciones y sanaciones, siempre entre todos y para todos. El funcionar comunitario era su forma natural de vivir en armonía con todos los seres vivos y la naturaleza circundante.

Sabían de traumatología, tratar las luxaciones, torceduras y fracturas, además practicaban trepanaciones de cráneo, como lo demuestran grabaciones incaicas. Su gran ventaja fue el acabado conocimiento de la herboristería, nuestros yuyos andinos, numerosas plantas medicinales que se siguen usando hoy y que los laboratorios europeos copiaron formulas para comercializarlas. La asistencia de los partos y toda la medicina llamada hoy perinatal, era muy desarrollada y son interesantes las descripciones de los tratamientos para todas las distocias y complicaciones postnatales. 
Colegas, busquemos lo sencillo del ejemplo del jueves de las comadres y sus comidas comunitarias, como manifestación ancestral del deseo de unión y vínculo simple del afecto con otros y entre todos. Mientras escribía esto, todas empezaron a enviarme nombres de comidas andinas típicas, como el locro, las humitas, los tamales, el charqui, el chuño, el patay, la chicha, el arrope de tuna o chañar, la aloja y añapa, el machacado, el cocho y otros. Entonces, María Laura sugirió hacer una reunión gastronómica regional, al estilo del Encuentro Cultural Alimentario, "Allinta mikhusun tarpusqanchjta”, realizado en Jujuy por la agrupación popular del “Tupaj Katari”, para que reunidas busquemos juntas ese momento único e inolvidable, convocando a otras y otros andinos, para descolonizarnos y recuperar lo nuestro, lo auténticamente latinoamericano.

Mi convocatoria es solo una forma de proponerles hacer algo entre todas y desde cada una, para amortiguar el tremendo efecto de la violencia en todas sus formas en nuestro país y nuestro continente. Pero revisando nuestra historia de pueblo avasallado y colonizado y nuestra profesión diseñada desde los claustros universitarios para conformarnos como agentes de mantenimiento del sistema, no como agentes del cambio social, tal como lo definieran nuestro inolvidable maestro José Bleger (1970) y Enrique Pichón Rivière (1980).

Recordando a Ignacio Martín Baró, vale reiterar su deseo de una psicología que abra espectro del conocimiento hacia el estudio sistemático y participativo de la diversidad cultural latinoamericana, como un pueblo colonizado y militarizado por siglos (Martín Baró, 1990a, 1990b, 2003, 2013). Pese a que sus ideas le costaron la vida, la paradoja es que son base para la convivencia social en paz, con respeto por lo diferente y la disminución de la monstruosa violencia que nos demuele día tras día.

Finalmente, me propuse un documento convocante pero se me calentó el pico de la mano y va queriendo ser un libro, que sin apuros este año podré terminarlo. En los retoques finales dudo haber comunicado lo que deseaba, so pena de mucha ingenuidad frente a lo embates de acontecimientos nacionales y sudamericanos de los últimos tiempos. Es posible, pero valió la pena en estos meses de mucha lectura y aprendizaje.

\section{Psicología andina para la liberación}

Pese al desarrollo de la ciencia y la técnica y lo que sus avances han hecho posible, la vida del planeta y de la humanidad se encuentran seriamente amenazadas, como resultado de una razón sin alma, de una ciencia que ha sido instrumental al poder y a sus proyectos de dominio de la totalidad de la vida. Quizás por eso, antes de ponernos sólo a pensar en qué titulo o qué profesión vamos a obtener en las universidades, lo que deberíamos seriamente es, desde el corazón, pensar (es decir, corazonar), para saber qué mundo y que horizonte de existencia le vamos a dejar a las niñas y niños que aun no nacen, a las hijas e hijos que aun no empiezan a transitar por los caminos del mundo y de la vida; deberíamos "sentipensar" que hacemos para sanar las heridas 
de la Pacha madre tierra, que hoy agoniza por la ambición de una civilización que prioriza el capital sobre la vida, y que está poniendo en riesgo las posibilidades presentes y futuras de la existencia.

Ahora más que nunca, se hace imperativo cuestionar radicalmente el sentido de cómo hemos estado construyendo el conocimiento desde una academia que se erige con arrogancia y la hegemonía de una razón carente de ternura, y no sólo que negó y subalternizó otras formas de conocer como las sabidurías andinas sino que, además, le ha proporcionado al poder los instrumentos teóricos y metodológicos para producir un conocimiento que ha sido instrumental al poder y la dominación,

De ahí que el modelo racional logocéntrico (la irracionalidad de la razón) es uno de las causantes de la situación actual que enfrenta el planeta. Resulta por tanto una cuestión de importancia no solo académica, sino sobre todo política, pues lo que está en juego es la cuestión de la existencia, la misma que para ser preservada requiere no solo de epistemología sino sobre todo de sabiduría.

Como ejemplifican Maturana y Varela (1994) en un zoológico de Nueva York, en un gran pabellón dedicado a los primates, chimpancés, gorilas, gibones y en una jaula especialmente separada con gruesos barrotes, dice "el primate más peligroso del planeta". Al mirar dentro de la jaula, un enorme espejo refleja el rostro de quien mira con la leyenda "el hombre que ha matado a más especies sobre el planeta que ninguna otra especie conocida". Una anécdota que señala la capacidad destructiva del ser humano, depredador de su propio planeta.

Coincido con los certeros decires del antropólogo ecuatoriano Patricio Guerrero Arias, cuando argumenta que "nuestros ancestros anunciaban la llegada de un tiempo en que el cóndor, símbolo del corazón y representante de los pueblos del sur del continente, llegaría a volar en el mismo cielo junto con el águila, que simboliza la razón, el pensamiento de los pueblos del norte. Pues como enuncia la sabiduría de nuestros "agüelos", solo cuando el corazón y la razón, el cóndor y el águila se hermanen en vuelo de libertad, la humanidad encontrará razones para sanar la vida y salvar a la madre tierra, pachamama, que hoy agoniza, por la voracidad de una civilización que ha dado prioridad a la acumulación del capital a costa de nuestra vida. Por eso estas anticipaciones ancestrales nos mostraban la necesidad de un vuelo conjunto de águilas y cóndores, en este tiempo de corazonar desde una perspectiva psicológica descolonizada y auténticamente nuestra (Guerrero Arias, 2004a, 2004b, 2012, 2017).

Extraigo conceptos de nuestro inolvidable colega salvadoreño Ignacio Martín Baró, asesinado por los "servicios del Norte": el saber psicológico debe ponerse al servicio de una sociedad donde el bienestar de los menos no se asiente sobre el malestar de los más, donde la realización de los unos no requiere la negación de los otros, donde el interés de los pocos no exija la deshumanización (Martín Baró, 2013).

Alguna vez leí que la sabiduría es ese saber espiritual de múltiples colores como el arco iris, que proviene de varias partes y que no solo emerge del cerebro y 
la razón, sino también de nuestra intimidad del alma y del corazón. Es parte del sentir en una "psicología andina para la liberación", sustentada en variados pilares de latinoamericanos, como la filosofía de la liberación iniciada en nuestro país a comienzo de los setenta, con los filósofos Enrique Dussel (1988), Rodolfo Kusch $(1961,2007)$ y Carlos Cullen (1986), a las que sumo las conceptos del sociólogo jujeño indio Osvaldo Maidana, la chilena india Gabriela Mistral (1962) y la pedagogía de la esperanza de Paulo Freire (1992), cuyo pensamiento sustentó mi libro Prevención comunitaria (Videla, 1994). Paulo, sonriente cuando lo conocí, me dijo "eres el resultado de la metamorfosis entre Sarmiento y Paulo Freire", mientras sostenía en su mano una empanada y un vaso de vino de mi tierra sanjuanina.

Por qué escribo sobre psicología andina, me han preguntado. Yo misma me interrogo al escribirlo. Parto del punto inicial por experimentar incomodidad, disconformidad y hasta desagrado por algunas teorías y practicas de la psicología en mi país y parte del continente sudamericano. Pese al concepto chauvinista de creernos el país mas psicologizado y psicoanalizado del continente "civilizado", parte de la petulancia nacional que nos caracteriza nos hace creernos mejores o más importantes, y actuar con absoluta ausencia de humildad. En lo que me atañe, después de más de seis décadas de vida profesional, de haber pasado por cargos y asesorías gubernamentales, docencia universitaria nacional e internacional, de ser docente en variadas culturas y de haber publicado veinte libros, tengo profundas dudas respecto a la eficacia del fundamento teórico de mi disciplina, una visión recibida en una universidad nacional argentina.

Suele ser difícil poner en palabras escritas lo que se siente, se piensa, se dice o se hace, con riesgo de que sólo sea un discurso teórico mas. Para ser franca, creo que escribo por una necesidad que se hace impulso para sembrar una psicología comprometida de verdad con nuestra vida latinoamericana. No como reto discursivo, sino como praxis transformadora que facilite no solo hablar por y para la salud, sino actuar por ella en amplia perspectiva. Por eso, estos escritos están hechos como en teclado musical al compás de varias manos y múltiples corazones que emergen de experiencias vividas y sentidas.

Me adentro en ideas para una psicología andina desde el saber de nuestros antepasados andinos, cuyos registros fueron destruidos por el tsunami colonizador, pero que no pudo borrar sus sentires, sus organizaciones comunitarias, sus pensamientos, su música y sus tradiciones que hoy se han recogido y revalorizado después de quinientos años de adormecimiento.

No uso citas del griego o del latín para explicar lo que los andinos pensaban y piensan de la salud, la enfermedad, la curación y la muerte. Textos actuales lo han registrado laboriosamente, como los de la socióloga salteña Maria Cristina Bianchetti (1996, 2017), el sociólogo Mario Vilca (Bugallo y Vilca, 2018), la antropóloga boliviana del movimiento tupac katari Silvia Rivera Cucicanchi ("sochologa": socióloga y chola) $(2015,2016)$, la colega salteña Alicia Torres $(2008,2016)$, creadora del concepto de psicología domiciliada, el colombiano Carlos Arando Calad (1995) con su psicología 
comunitaria para la convivencia, Adolfo Colombres (1996) en su antropología social de apoyo y la mexicana Ana Luisa Guerrero Guerrero (2016) en su magnifica obra sobre filosofía indígena y derechos humanos.

No se trata de reflexiones teóricas y abstractas ni de tecnologías impuestas a presión, importadas de Europa e inconsultas con la población afectada, sino de lo tejido con los mismos actores sociales de quienes aprendimos lo que sabemos. En las ciencias humanas, hoy todo debe ser cuantificable, tecnocrático y estadístico, en claustros académicos que ya no hablan de liberación sino de acreditación con demandas académicas que responden al mercado cognitivo, impuesto por las transnacionales del conocimiento, para alcanzar valoración académica, para elevar prestigios personales que cumplan el síndrome de la pandemia de la "egofrenia" profesional que padecemos.

La medicina tradicional andina, sustenta la salud en el equilibrio cálido-frío y el pensamiento animista del mundo, su metodología es explicar el sentido holístico de la vida, donde los agentes tradicionales de salud asumen su rol como un don natural y basan su intervención en la restitución del equilibrio con rituales y plantas medicinales. Queda claro que la forma y la sanación andinas no se respaldan en el dualismo tradicional cartesiano de mente/cuerpo.

Por eso asombran textos recientes de psicoanalistas argentinos, intentando explicar la cosmovisión andina con los preceptos de Lacan. Empresa complicada intentar traducir o equiparar el psicoanálisis nacido en Europa, con nuestra cultura originaria, avasallada y diluida con el impulso europeizante colonizador. Sobre todo porque no se tiene en cuenta el área de los afectos espirituales, las emociones y el marco sociocultural sensible que nos enmarca. Opino que se trata de nuevo un intento de colonización europea, avasallador de nuestra cultura original a la que definen como "salvaje", tal como hiciera el clero católico de la conquista con los pobladores que se negaban a bautizarse y someterse al credo católico papal, pagando con torturas y hasta con su vida su resistencia al credo invasor.

Otro autor, egresado de la Universidad Nacional de La Plata, exilado en la dictadura de los setenta, que ha producido textos que conmueven y enorgullecen, enmarcados dentro de la propuesta de una psicología andina, es Oscar Strada (2017), quien acaba de publicar un texto donde rescata la amistad como forma de contrarrestar la violencia, con un programa de prevención desarrollado en el ámbito escolar en España, coincidente con las propuestas docentes de la antropología del corazón ecuatoriana.

Tomo el tema como "psicomedicina andina", como enfoque de avanzada. Así como los pueblos tradicionales de los Andes son extremadamente variados, su cosmovisión y su sistema de salud presentan múltiples matices. A lo largo de siglos de existencia, la actual sociedad de los Andes, desarrolló una serie de conocimientos y prácticas para conservar y recuperar la salud de sus integrantes. Muchos de esos conocimientos y prácticas provienen de aquellos gestados en la etapa de consolidación del Imperio Inca, otros deben haber nacido en otras culturas andinas. Todos ellos 
han permanecido en el tiempo a causa de su utilidad y eficiencia, puesto que cada sociedad, independientemente de cuál sea su origen, desecha tarde o temprano aquello que no le es útil para sus vidas. Como todo sistema, el fundamento del sistema de salud andino contemporáneo es una concepción o representación de lo que es estar sano o tener salud, que integra dos elementos claves: la condición individual y la condición colectiva. La tecnología que fue tan lejos desde el descubrimiento del fuego, las herramientas y los aparatos, colaboraron para que el hombre viviera mejor y sobreviviera como especie. Lejos estamos a comienzos del milenio, con la "biotecno-ciencia", que inunda a la medicina y la psicología moderna tan soberbia en sus saberes absolutos y su abanico de certezas.

En el noroeste argentino existe una abundante gama de padecimientos en salud mental bajo denominaciones culturales propias, donde los afectados son responsables de su propia enfermedad, consecuencia de inobservancias o violaciones de tabúes en relación con las entidades rectoras de los medios donde desarrollan su vida. Otras afecciones aparecen como resultado de encuentros no deseados con entidades sobrenaturales o sus representaciones, de las que no están exentas las áreas urbanas. Esta variedad de afecciones, muchas de ellas envueltas en un manto de concepciones mágicas o sobrenaturales vigentes aún, son reconocidas como males del susto, del espanto, del agarre, de aikadura y pilladura, o simplemente como "el mal de" entre otras tanto en las áreas campesinas como urbanas o periurbanas. Dedico capítulos de mi libro, sobre el tema de la salud mental en la cosmovisión andina que me encuentro escribiendo.

Revisando bibliografía de mujeres sudamericanas redescubrí a Gabriela Mistral, a quien nos la destacaron como poeta y premio novel de literatura, pero nunca como feminista y exponente político del género de nuestro continente en el siglo pasado, un típico efecto del "memoricidio", con el que asesinamos la memoria en ideas de quienes no se ajustan al sistema dominante. La concepción social de la Mistral se basa en "tierra, indio y mujer". Ella jamás quiso deshacerse del indio que corría por sus venas, como tampoco del español que la constituía. Sin embargo, en su interior privilegió al indígena. De él obtuvo sabiduría y misticismo, a través de él logró conexión con lo natural, heredó el don de la paciencia y la virtud de la reflexión. La defensa que hace del indígena tiene que ver con el propio reconocimiento; a partir de su identificación como india. La combinación de las sangres milenarias que la atraviesan son el impulso vital que la instan a profundizar y reflexionar acerca del significado del mestizaje, conjuntamente con la dosis del olvido que carga. Se puede decir que Gabriela nunca sintió la necesidad de escapar del manto indio que la cubría, sino que, todo lo contrario, lo destacó e hizo gala de él. Una vez asumida como india, Gabriela no cesó de criticar a aquellos que intentaban olvidarse de su esencia, y no dudó en lanzar dardos directos a los mestizos y latinoamericanos que reniegan de la sangre india que los constituye.

Para Gabriela, la tierra no es algo ajeno a las personas, está allí y su cuidado es responsabilidad de todos. Anticipa los movimientos ambientalistas de nuestra época, 
pero en su discurso no busca confrontarse nunca con nadie. Sólo pretende remecer la pereza de los hombres y mostrarles el sentido perdido de la vida:

"La tierra que está baldía hambrea y envilece a su gente, pero el daño no se lo provoca a sí misma. Es el hombre quien no se ha encontrado con la esencia de la felicidad: donde la tierra es bárbara de matorral ciego y de peñascos, está bárbaro el hombre, aunque tenga escuelas, plazas y portadas ostentosas de haciendas. El hombre fue entrando en la barbarie porque perdió el vínculo sagrado que lo unía a la tierra. El principio de sabiduría de los primeros pueblos agrarios fue reemplazado por la técnica y la mecánica. Hay que saber, para aceptar esta afirmación, lo que significa la tierra para el hombre indio; hay que entender que la que para nosotros es una parte de nuestros bienes, una lonja de nuestros numerosos disfrutes, es para el indio su alfa y su omega, el asiento de los hombres y el de los dioses, la madre aprendida como tal desde el gateo del niño, algo como una esposa por el amor sensual con que se regodea en ella y la hija suya por siembras y riesgos. Según esta concepción el hombre blanco no ha sabido comprehender el carácter sabio, fecundo e intenso que la tierra exhala con cada latido de la naturaleza, no llegaremos nunca al fondo del amor indígena por el suelo, que hay que estudiar especialmente en el indio quechua, maestro agrario en cualquier tiempo" (Figueroa, Silva y Vargas, 1990, pp. 25-26).

La defensa de Gabriela del indio, la tierra y la mujer, se hace desde banderas de los pueblos originarios, dueños de tierras despojadas. Era una mujer hermosa, mezcla de aborigen y catalana, de 1.80 de estatura y hermosos ojos verdes con rasgos indios innegables. Tuvo dos amores importantes y perdió un hijo de pocas semanas, cuyo dolor se evidencia en los hermosos poemas dedicados a los niños y la maternidad. La sociedad chilena de comienzos del siglo pasado, no le perdonaban ser tan inteligente, creativa y autónoma, como para haber llegado a ser la primera mujer latinoamericana con premio novel de literatura. Por eso la etiquetaron como lesbiana y comunista, para esa época un insulto. Ella fue excelso representante de la psicología andina por su defensa de la identidad india, de la que no renegó, su lucha por la tierra despojada por los colonizadores y las mujeres que han tardado un siglo después de ella para ocupar el lugar merecido por siglos mancillado. Sus ideas sociales la mantenían en constante preocupación por los niños mas necesitados. Por eso legó a los niños de su ciudad del Valle del Elqui, todos los derechos autora que le sucederían. Durante la dictadura de Pinochet lo quitaron.

La andina Silvia Rivera Cusicanqui, socióloga y activista boliviana anarquista, de ascendencia aymara, vinculada al movimiento indígena katari y al movimiento cocalero, junto con otros intelectuales indígenas y mestizos fundó el Taller de Historia Oral Andina, grupo autogestionario que trabaja temas de oralidad, identidad y movimientos sociales indígenas y populares, principalmente en la región aymara. La noción aymara "chi'ixi" quiere decir "gris", contaminado, mezclado (Cusicanqui, 2018). Es la mancha india que tiene todo el mundo y se refiere al mestizaje 
descolonizado y orgulloso de sus raíces, tal como lo manifestara Gabriela Mistral. A partir de sus investigaciones, Cusicanqui presentó su "Oralidad Ideología étnica en los Andes", donde observa reticente la nueva escena desarrollista indígena en el contexto político actual de Bolivia. Para la socióloga, ante la explosión de identidades políticas indígenas en Bolivia, se produce una visión tecnocrática de lo que es la convivencia entre diferentes. En "Oprimidos pero no vencidos" manifiesta necesario entender que lo indio es parte de la modernidad, que no es una tradición estancada, estática y petrificada, sino que es una dinámica de interacciones conflictivas con poderes coloniales de diversa escala (Cusicanqui, 2016). Desde las "realidades" étnicas cree necesario dejar de lado miradas patrimoniales de lo indígena, para reconocer cómo las resistencias y autonomías de estas comunidades se ven afectadas por las perspectivas desarrollistas. Esto significa comprender que

(...) la modernidad de los indios nos ayuda a entender que no se trata de rescatar identidades arqueológicas, de encerrarlas en museos de la diversidad, sino de entender esas ideologías dinámicas que dialogan permanentemente con la modernidad y que hacen uso de todos los medios que ofrece la modernidad (Cusicanqui, 2016).

Como integrante de la cultura aymara, Cusicanqui distingue lo que sería un discurso "miserabilista" de la memoria étnica y un discurso que respeta al sujeto indígena. Por esto declaró tener reticencias con la idea de colonialidad y prefiere hablar de "colonialismo interno" porque tiene una doble connotación: está internalizado. No podría ser tan eficaz el colonialismo si no fuera porque nos hemos metido el enemigo adentro, es por eso que nosotros buscamos superar esa visión miserabilista de la memoria como lamento, sin trivializar el dolor. Se trata de reconstruir la memoria de la cultura indígena en contextos contemporáneos. A través del análisis de imágenes que han representando históricamente lo indígena y su relación con el poder en Bolivia, esta socióloga reconstruyó representaciones del poder desde los incas que han sido imaginados como "héroes solitarios" hasta publicidades políticas del actual presidente Evo Morales, donde lo indígena es "estetizado en el vestuario".

Cusicanquiaseguraquenohaymacromovimientosrevolucionarosteóricosodirigentes próceres, porque hace agua la idea de revolución, pero hay "microfragmentos" en medio de la macro violencia actual, que construyen "pequeños amaneceres", en este oscuro mundo actual que no es del hombre nuevo sino de la "nueva mujer". Ella insiste en que es necesario "feminizar las utopías", buscando nuevas palabras que manen de la sangre aún no digerida, para evitar estallidos de furias. Condición necesaria es descolonizar la mirada hacia el sur andino, propuesta que me estimula a desarrollar mi pensar en una "descolonización" de la psicología, por su tóxico europeizante que domina, para construir un concepto nuevo de "psicología para la liberación", basada en una versión laica de la filosofía de la liberación y el pensamiento de muchos sudamericanos.

La filosofía de la liberación es solo una de las bases conceptuales para la propuesta de 
la "psicología para la liberación" desde la nueva perspectiva para una de la psicología andina. La situación de Sudamérica se deteriora en 1971, fecha en que surge en Argentina la filosofía de la liberación latinoamericana, a partir de la injusticia estructural que oprimía a las mayorías populares de nuestro continente. Hoy la exclusión se muestra más injusta, creadora de más víctimas que la explotación, junto a una globalización promovida según la ideología neoliberal que se auto-proclama "pensamiento único".

La filosofía de la liberación es una opción teórica y ético política para los excluidos, se concreta en una opción por éstos, sean pueblos, grupos sociales o individuos, que representan de hecho la mayoría del mundo global y de Sudamérica. Por otro lado, nuestro subcontinente, aunque no es el más pobre de la Tierra, es aquel donde las desigualdades y la inequidad son comparativamente más indignantes. Así se dio inicio a este movimiento filosófico, cuyo impacto, con todo, no fue tan amplio como el de la teología de la liberación, aunque se extendió aun fuera de Latinoamérica. Se entrelazó con intentos ya existentes, como la búsqueda de una "filosofía americana", la filosofía a partir del "pensamiento indígena y popular", la historia de las ideas en Sudamérica y la reflexión acerca de los presupuestos filosóficos de la teología de liberación. El argentino Dussel (1988), uno de los fundadores de la filosofia de la liberación, señaló con las dos palabras el título de su última ética: "globalización" y "exclusión", dos importantes momentos de la nueva cuestión social. Primero, una globalización promovida según el "pensamiento único" neoliberal. Segundo, una de las consecuencias más funestas de éste para la persona humana, la exclusión fuera del sistema económico global de millones de personas, de decenas de países y aun de continentes enteros, como África subsahariana. La máxima expresión de la exclusión son el desempleo estructural y la precarización del trabajo.

La obra de Rodolfo Kusch fue un valioso aporte a la interpretación de la cultura americana. Sus investigaciones de campo sobre el pensamiento indígena y popular americano fueron el fundamento de su reflexión filosófica. En el mundo globalizado en que vivimos, donde la tecno ciencia intenta dar todas las respuestas y los fenómenos de segregación se multiplican, conviene revisar la otra perspectiva de la condición humana. Sin embargo, la novedad de la situación se manifiesta en rasgos positivos, en el momento actual y que también dan que pensar. Pues, el peligro militar ha pasado en América Latina y la democracia, aun frágil, es sólidamente apreciada después de la dolorosa experiencia de la represión de las dictaduras. Los pueblos latinoamericanos muestran signos de resistencia cultural a los uniformados, en medio de un siempre mayor pluralismo ético, cultural y religioso. Otra novedad muy positiva es el lugar social cada vez más reconocido y valorado, de la mujer, de cuya liberación ya hablaba Dusssel en su "erótica latinoamericana".

La amenaza hacia lo humano ha facilitado una mayor conciencia de los derechos humanos, no sólo civiles y políticos, sino también sociales y culturales; la ética ha resurgido como preocupación, aplicándosela a la relación con el medio ambiente, a las investigaciones y manipulaciones genéticas, a la responsabilidad social de 
la empresa, a la relación entre las culturas. Ante la crisis del Estado de bienestar y la amenaza de la "tiranía del mercado", se generó universalmente y en América Latina, un nuevo fenómeno del despertar de la sociedad civil, que se auto-organiza en ONGs, voluntariados, grupos populares organizados alternativos de reflexión, de participación y acción ciudadanas y de presión, en movimientos sociales como los "sin tierra", piqueteros, movimientos indígenas, organizaciones barriales y comunitarias, creando redes de solidaridad tanto provinciales, barriales, nacionales como internacionales. Se trata de nuevos agentes y sujetos históricos, llevando a cabo un nuevo modo de hacer política, no partidaria. Es decir, se mueven en el espacio público no estatal, del bien común. Se preocupan por intereses universales: los derechos humanos, el trabajo, la justicia, la lucha contra corrupción política, la impunidad jurídica, la violencia y la crueldad social, la ecología. Se buscan bases alternativas viables al neoliberalismo, sobre todo en lo local, es decir, en el barrio, el pueblo, la parroquia, el municipio, sumando un "pensar en global" con un " actuar en local".

Se trata de un fenómeno típico de reacción superadora de la globalización neoliberal, que pone en juego la creatividad de los pobres y excluidos, así como de la clase media empobrecida, los "nuevos pobres". Es una nueva modalidad de la astucia y sabiduría popular latinoamericana, que toma cuerpo social en nuevas organizaciones libres del pueblo. Éstas van así rehaciendo el tejido social e institucional, fragmentado por el individualismo competitivo. El nacimiento de la "ética de la liberación latinoamericana" al comienzo del tercer milenio, con dilemas a desatar, aparece por Enrique Dussell (1988), con una ética que se inspira en lo popular latinoamericano. Desde él se puede apreciar nueva mirada diferente, descolonizada de la historia "mundial", donde Europa ya no es el centro, ni el fin de la historia. Una historia no eurocéntrica, donde las naciones y las culturas adquieren una real dimensión. Se desacraliza la historia que aprendimos en nuestra educación básica y se rescata el valor de las naciones y culturas no europeas. Es trascendente dimensionar la verdadera importancia de naciones y culturas no occidentales. Porque hay cultura más allá de la Europa que nos enseñan en la educación oficial, olvidando los orígenes prehispánicos, los aportes culturales de los humanos que habitaban el territorio que hoy ocupan los países andinos.

Es esencial descolonizar la enseñanza de la historia eurocéntrica, para enseñarla mostrando lo nuestro, aclarar que no hubo un descubrimiento de América, pues ésta ya estaba descubierta y poblada por los pueblos mesoamericanos, que no ocurrió un encuentro sino un genocidio cultural, que destruyó casi toda la cultura y memoria de los pueblos mesoamericanos, cuya herencia sobrevivió poco hasta nuestros días. La arqueología ha estado rescatando a esa cultura y memoria destruida por los españoles, que invadieron el territorio mesoamericano de forma violenta. Una historia no eurocéntrica debería de enseñarse en todas las escuelas sudamericanas, una historia diferente a la que se enseña desde la primaria hasta la universidad. Tal es lo que sucede en la educación del Ecuador en un programa de revitalización de la cultura, las identidades y las memorias vivas de los pueblos y las nacionalidades indígenas. 
La razón de la hegemonía social y cultural capitalista, dice que la satisfacción de nuestras necesidades y nuestros deseos pasa por la posesión y el uso de bienes y servicios que nos proporciona el mercado. Según el imaginario colectivo, entonces, hay una correspondencia directa entre la "riqueza" y la "felicidad", la abundancia y el bienestar. La sociedad de la economía del crecimiento y del bienestar, se basa en la caducidad, tanto para las mercancías, del "usar y tirar" pasado a desperdicios, como a las personas, excluidas de "usar y despedir", desde el obrero al ejecutivo, desechables hasta los desocupados, marginados, indigentes y otros residuos sociales actuales.

En una sociedad de crecimiento, los que no son ganadores, los que no avasallan, son excluidos en mayor o menor medida. El decrecimiento, al igual que promueve el reciclaje de desechos materiales, también debe interesarse por la rehabilitación de los excluidos. Y si el mejor reciclaje consiste en desechar menos, la mejor forma de rehabilitación social consiste en evitar la exclusión.

Mi colega amigo Aldo Schlemenson (2007) decía en su "Estrategia del talento" que la humanidad vive un proceso de regresión, donde ha pesar de la eclosión del conocimiento, la ciencia y la tecnología, las redes sociales, la conquista el espacio y la longevidad, han quedado sin resolver la violencia, la injusticia, la inequidad, la corrupción y la crisis de valores. Esta disociación el la suponía potenciadora de la alineación. Sin duda que nuestro Aldo tenía razón.

Ignacio Martín Baró aporta "las raíces de la convivencia social se encuentran gravemente deterioradas. ¿Y cómo no las iban a estar en un medio donde impera el recurso de la violencia para resolver las diferencia interpersonales e intergrupales, donde el sentido común ha sido sustituido por el sentido partidista, donde la irracionalidad ahoga las posibilidades de contactos humanizadores entre sectores distintos e impide el desarrollo de una normalidad cotidiana? (Martín Baró, 1990b).

La propuesta de una "psicología andina para la liberación”, es una movida destinada al rescate de nuestra cultura originaria, excluida y borrada por el efecto demoledor del avasallamiento de la corona de España y las misioneros del Estado Papal, que eliminaron los registros de nuestra cultura y sus formas de vivir, enfermar, sanar y morir, forcluída hasta el presente por los nuevos colonizadores colonialistas, los misioneros del fondo monetario internacional.

Ante los múltiples sufrimientos del mundo actual no es suficiente evaluarlos como causas de patologías mentales y proponer las psicoterapias tradicionales que se enseñan en nuestras universidades, tan bien cuestionadas por el antropólogo argentino Eduardo Menéndez en su genial enunciado del "modelo profesional hegemónico", formando intramuralmente carradas de profesionales con la esperanza clínica del posible paciente individual, tal como prometen los textos europeos en sus bibliografías usadas en nuestras carreras nacionales de psicología, con un sistema histórico, político y social diferente a las demandas para nuestra región (Menéndez, 1987, 1998, 2000).

Nuestros modelos de formación académica nacional excluyen, reducen y desvalorizan a la psicología social, la prevención y la psicología comunitaria, con todos los 
desarrollos teóricos de nuestro país y del continente sudamericano. Sus bibliografías se reducen a trabajos y textos norteamericanos y europeos. Se desconoce y excluye más de medio siglo de trabajos al respecto en sudamérica. Basta con recordar que durante la dictadura argentina estuvo prohibido hasta Paulo Freire, pero por siglos nuestra manera de pensar fue anulada y censurada por todos los avasallamientos colonizadores que hemos padecido y aún permanecen entre nosotros.

Me ha tocado en lo personal vivir una experiencia frustrante en la Facultad de Psicología de la UBA. Ya llevaba treinta años de experiencia en Prevención Primaria y varias publicaciones sobre salud materno infantil, pero debí soportar con indignación que un jurado declarara desierto el concurso por asegurar textualmente que yo sólo era "especialista en prevenir embarazos" y remarcara mi falta de bibliografía de la escuela francesa de psicoanálisis. Como hago habitualmente ante un fracaso sísmico, salí de los escombros de la frustración escribiendo mi libro "Prevención", que me ha dado mucha más satisfacción que una cátedra en los claustros europeizados de la UBA. Uno de los ellas fue la emoción y orgullo al saber que este libro era usado por el movimiento comunitario Tupac katari de Carlos Santillán, para su trabajo social comunitario y político en Jujuy, junto a su compañera Fernanda Cieza, colega psicoandina, egresada también de la UNLP.

Propuestas actuales nos marcan derroteros diferentes, latinoamericanos, como la espiritualidad, posible mirar del vivir para sacarnos de cegueras que no nos permiten observar el horror del mundo construido por razón colonial. Se requiere de un sistema de valores éticos y morales que alivien las situaciones conflictivas, dando lugar a principios como la sabiduría popular, la compasión, el amor, la ternura, la pasión, la honestidad, el desapego, la armonía, el equilibrio, la honestidad, la serenidad, la ecuanimidad, el silencio, la generosidad, la lealtad, el amor hacia nosotros y los otros, la reverencia y gratitud por la vida para poder vivir con humildad y sencillez, valorar más el ser y no el tener, tener cooperación y coherencia, impecabilidad, enseñar con el ejemplo, buscar felicidad con paz, la liberación social e individual, conservar la capacidad del asombro, emoción ante el sufrimiento, poder maravillarnos ante la belleza, para todos descubrir a pesar del dolor, el sufrir y la miseria, una poética que habita en todos, para despertar el corazón y la ternura que hace posible soñar con una existencia diferente.

Coincido en que la búsqueda de lo nuevo en ciencias sociales no consiste en buscar nuevas tierras, sino en tener nuevos ojos. En este caso los ojos del corazón, símbolo corporal humano de los sentimientos. Patricio Guerrero Arias, opina:

Queremos aportar no al rescate de la cultura como acto colonizador, sino a la revitalización de nuestra cultura, identidad y memoria, porque la cultura es una fuerza que ha hecho y hace posible la reafirmación y transformación de la vida, porque ha sido la fuerza de nuestra cultura, de nuestra ancestralidad, las que nos ha permitido a pesar de tantos siglos de opresión y de muerte, seguir existiendo y hablando con palabra propia, por lo que revitalizar nuestra cultura es un acto liberador (Guerrero Arias, 2004a). 
He tomado ideas de esa "antropología corazonada" de Guerrero Arias para aplicarlo a la psicología, con aportes de autores que lo amplían y desarrollan hacia el mismo objetivo en la recuperación de los sentimientos y la espiritualidad de la cosmovisión andina.

"Corazonar" y "ternurar" desde la mirada de la salud mental andina, significa elegir huellas de simplicidad voluntaria para eludir la sociedad de consumo y organizar nuestra vida con la esencia del nosotros, más que del uno, alejarnos del singular extremo para arribar al plural, porque poder sentir empatía con los demás implica relación con la comunidad de nuestra vida y con otras especies, con toda la naturaleza y con futuras generaciones. Esencia de la filosofía andina ancestral.

Los gérmenes aportados en el pasado, en nuestro "jardín de los sentires", estarán floreciendo en un futuro que estamos creando los psicoandinos. Se trata de una mirada simple del existir, excluyendo la acumulación de recursos materiales y adquisición de posesiones, confundiéndolo con calidad de vida o bienestar. Para este sentir andino se requiere de personas que valgan por lo que sienten y no por lo que acumulan, adictos al consumo, amasar dinero o prestigio profesional, sin importar el cómo ni a costa de qué se logra. Somos víctimas de esa "egofrenia", pandemia de nuestra época, que ha contaminado a los profesionales argentinos, incluidos los psicólogos, muy lejos del poder llegar a trabajar en algo elegido y satisfactorio, que permita ejercer fundamentalmente al servicio de otros y no para uno exclusivamente.

Buena sería una conexión intima y espiritual para acariciar la existencia simple, conscientes del universo que nos rodea y nos sostiene. Se puede vivir sencillamente rodeado de todo lo que vive y la Pacha naturaleza generosamente nos ha regalado. Nos cuenta muchos sacarnos la piel de la razón, negando la afectividad, pues para lograr el dominio de la naturaleza y de los humanos, no es posible sin la ternura corazonada.

La psicología andina es una propuesta espiritual y política para descolonizar el poder, saber y ser, como curación de nuestra vida por tiempos en que debemos interrogarnos acerca del sentido teórico, metodológico, ético y político sobre nuestro quehacer como profesionales de la salud mental en Sudamérica. Es el resultado de los procesos de luchas de nuestros pueblos que históricamente padecieron dominación sobre sus cuerpos y sus espíritus, desde donde surge la necesidad de comenzar a mirar desde la fortaleza de la sabiduría del corazón, para construir un nuevo horizonte a la existencia humana.

La colonialidad, matriz colonial imperial, vigente desde la conquista invasora, continua operando en tres niveles: del poder politico, del control de la economía, la cultura, la naturaleza, lo científico, la subalternacion de las lenguas y los conocimientos, la sensualidad, la subjetividad, la sexualidad, los imaginarios y los cuerpos, a fin de lograr el control absoluto de la vida. La razón es sustento de un orden patriarcal, falocéntrico, de dominación aún actual, necesario para el dominio masculino de la vida, pues el conocimiento es identificado con la razón y lo masculino, por lo cual estaba vedado el acceso al conocimiento a las mujeres, los niños y a los pueblos evaluados como "inferiores", tal como se piensa a las comunidades originarias de Sudamérica. 
Una postura que presenta una manera diferente de visualizar al ser humano, ya no será el "pienso luego existo" sino más bien "existo porque siento". La psicología andina propone revitalizar la afectividad, el sentido espiritual de la vida, la dimensión femenina de la existencia y el capital de las sabidurías del corazón, negadas por efecto de la dominación colonizadora avasallante.

Viajando por Latinoamérica encontré en una vieja librería de Medellín, un libro de Carlos Luis Restrepo, psiquiatra colombiano, El derecho a la ternura (Restrepo, 1994). Sus propuestas por defender el derecho a ternurar la pareja, la vida familiar, la educación, la medicina y la política, me sirvieron de sustento para escribir mi libro "Credo por la ternura en tiempos de violencia", que publicara en Koyatum (Videla, 2010). Allí pude explicar la diferencia entre amor y ternura, conceptos que utilizo en mis grupos de familias esperando un nuevo miembro. Desarrollo la idea que alrededor del nacimiento se ha producido un verdadero mercado destinado a la mujer gestante y parida, que le venden no solo objetos diversos, sino las funciones que naturalmente asumimos como hembras humanas desde que el mundo existe.

Mi tarea contracultural en psicología perinatal es restituirles la confianza en sus propias capacidades, por encima o por debajo de la opinión de médicos obstetras, pediatras, puericultoras, psicólogas especialistas y hasta periodistas adictos a la "opinología" materna. Se ha convertido en un buen mercado de nuestro sistema económico, del que participan facilitándole las universidades que siguen excluyendo el tema o aplicándolo en un pequeño sector de materias optativas y cuatrimestrales, para generar redes, escuelas, escuelitas, cursos, cursillos, textos y manuales presenciales u online.

Me he dedicado al tema de la ternura hace unos años. Se diferencia del amor porque es un sentimiento generoso, no posesivo como el amor, sino que percibe al otro como diferente y reconociendo sus necesidades y derechos propios, por fuera de los vínculos especulares que se manifiestan en la pareja, las relaciones entre padres e hijos, docentes y alumnos, médicos y pacientes, como también en el ámbito de la política. Opino que estamos faltos de ternura, sentimiento básico para escucha a los diferentes, sin intentar asimilarlo fuerza a lo propio, causa de la famosa grieta social que padecemos tanto en nuestro país. Vivimos universos donde el poder coloniza al ser, oscurece la vida y llena de sombras para que no podemos observar el horror de la dominación y no podamos interrogarnos y luchar contra ella en este egoísmo irracional irrefrenable. Se nos impone ser competitivos en el mercado, agresivos en los negocios, con padecimientos de emociones destructivas como envidia, odio, miedo, venganza, rencor, violencia, crueldad, motores desencadenantes de enfermedades espirituales individuales y sociales.

Fue grato este encuentro con el pensamiento del ecuatoriano Patricio Guerrero Arias, cuyos bellos textos me acercaron colegas, incluidos manuales usados en los colegios para corazonar la historia andina en el sistema educativo. Devoré sus páginas descubriendo este novedoso movimiento antropológico, que se instaló a partir de una plataforma religiosa y me he encargado de laicizar en sus reflexiones, para intentar aplicarlas a la psicología andina. Me dejé penetrar entonces por estas propuestas para 
intentar enlazarlas con las propias y de otros autores latinoamericanos, como Oscar Strada de Argentina y Carlos Restrepo de Colombia. Me preñaron ideas que facilitan entrar en el universo de esta propuesta de "psicología andina para la liberacion", esos respaldos teóricos latinoamericanos de absoluta excelencia, de ideas que adhiero totalmente. Exquisitas formas del pensamiento transdisciplinar, entre antropología, historia, educación, psicología, sociología y el saber popular, todos al servicio de lo andino, como así mismo charlas con amigos y familia que adornan mi corazón y mi pensar de andina.

Estas ideas no tienen manuales ni técnicas de tratamientos para imitar, porque no es una teoría ni cuerpo teórico específico, sino sencillamente una manea del sentir y del mirar lo que nos sucede a las personas en este continente, en estos tiempos invadidos por tantas violencias, inequidades, crueldades, carencias e injusticias, que nos han infectado de desesperanza generalizada y egofrenias, casi como una pandemia continental. Ha llegado el momento de descolonizarnos, dejar de alimentarnos solo de reflexiones y teorías cada vez más alejadas de la realidad, para empezar por nutrir la frialdad de las teorías con el calor de los sentimientos.

Corazonar y ternurar son verbos psicoandinos, conjugaciones sanadoras para padecimientos que hoy nos aniquilan, como la crueldad, el individualismo feroz, la desconfianza y la corrupción generalizada, con total perdida de confianza en todos los niveles de vinculaciones humanas. Condición básica según lo reiteraba Aldo Schlemenson en sus textos (Schlemenson, 2007).

No podemos aliviar el padecer psíquico de quienes nos demandan por ayuda, sin el amor necesario hacia ellos. Precisamente es imperioso revisar las posturas hegemónicas que invaden el quehacer profesional de los psicólogos sudamericanos, formados y adheridos a un modelo capitalista de los servicios para la salud mental como mercancía, con la feroz competencia entre las variadas empresas de sistemas prepagos en salud, con ausencia de un sistema nacional para todos, sobre todo las poblaciones mas carenciadas que aumentan día a día en nuestro país, enfermando y muriendo a la buena de dios y con ausencia de los poderes políticos de turno, de cualquier color.

Corazonar y ternurar no son neologismos, sino propuestas de romper la fragmentación de lo humano, producto de la cultura impuesta por la colonización europea. No se trata de borrar las razones sino nutrirlas de afectos, para purgarla del carácter perverso de lo colonial, recuperando nuestras propias palabras. Hablamos de corazonar, uniendo corazón y razón, porque se propone "pensar con el corazón y sentir con la mente", para rescatar el modo de sentir de estas tierras latinoamericanas, silenciadas y avasalladas por más de cinco siglos.

Se requiere dialogar con respeto, amor y ternura, por todo lo que palpita vida, para escuchar y aprender de esas voces de la naturaleza y del cosmos, en lugar de tratar de aniquilarlo cada día más. Como dice la socióloga salteña Cristina Bianchetti, los fenómenos naturales forman parte del ser, vegetación, animales y fuerzas naturales. Nuestra salud y bienestar proviene del equilibrio natural con el medio donde cada uno vive. Por eso cuando una persona se enferma también se enferma su familia y su 
comunidad. Porque la tierra no pertenece al hombre sino que el hombre pertenece a la tierra y todos vamos enlazados como sangre, de familia. Por eso todo lo que le sucede a la tierra le sucede a los hijos de la tierra Pacha (Bianchetti, 2017).

\section{Algunas reflexiones finales}

Es necesario poner en marcha un ejercicio que permita bajar los niveles de ansiedad generados por la incertidumbre, que dificultan la adaptación a los cambios en una atmósfera social poblada de falsas profecías de los político para destruirnos mutuamente, rumores que favorecen grietas y fracturas, estados de animo negativos y desesperanzados que retroalimentan la crisis, entendida como inestabilidad y ruptura.

Por eso proponemos una psicología andina para la liberación desde nuestros sentidos, no desde nuestro cerebro. Recuperar dimensiones simbólicas del cuerpo, de la comida y los olores, que nos demuestren la sabiduría de los sabores y el sabor de la sabiduría, requiere acercarnos a las emociones, las sensibilidades, el género de lo masculino y lo femenino, la risa, la sonrisa, la carcajada, la alegría, la pena, los temores, las sensaciones agradables, todo el contexto sensible posible de lo humano. Porque no somos lo que pensamos sino lo que sentimos. La religión es dogmática porque aprisiona y puede hasta enfermar, la espiritualidad trata de liberar y sanar, porque no somos seres humanos viviendo experiencia espiritual, sino seres espirituales viviendo una experiencia humana. Existe equívoco muy generalizado de creer que la espiritualidad solo tiene que ver con cuestiones de lo religioso o que la religión tiene el monopolio de la espiritualidad. Alejado de la verdad, porque la religión y sus instituciones, han estado ligada al poder y se ha mostrado intolerante, sectaria, dogmática y por defensa de la supuesta verdad revelada de sus dogmas, ha justificado injusticia y dominación, genocidios y en nuestro país cómplice de la tortura en el terrorismo del Estado.

Guerrero Arias dice que ninguna religión es capaz de llevarnos a la espiritualidad o a la libertad, porque las religiones son causa de la esclavitud del pensar, que pueden ofrecer una religión como prisión o jaula. A esta altura de la existencia humana y la historia de la humanidad, es imprescindible andar libres y tenemos que soltar las muletas. Las religiones son intereses creados de la creencia organizada para separar y dividir a las personas, se basan esencialmente en el miedo y el castigo por pensar, desde la fábula de la manzana y la serpiente del paraíso.

Otro equívoco es asociar la espiritualidad con misticismo, pues se puede ser espiritual sin llegar a experiencias místicas. Visualizar el misticismo como ligado a la religión, es como creer que la espiritualidad es antagónica con el ateísmo. Por lo contrario, puede haber ateos que tengan una visión y praxis más espiritual de vida, así como creyentes que asisten frecuentemente a los templos, pero están alejados de lo espiritual.

La psicología andina es un camino espiritual no religioso, no tenemos nada que ver con las religiones, no se trata de imponerle dogmas a nadie, ni infundirles miedos 
ni amenazas terroríficas para que sean sumisos, o que no pequen porque se van a quemar en el infierno. No se trata de ofrecemos una imaginaria mejor vida en el más allá, sino buscar vivir la belleza de una buena vida del aquí y ahora, en este Pacha, en este tiempo, en este espacio de latinoamericanos, hermanados por siglos de exclusión $\mathrm{y}$ ninguneo.

Proponemos no vivir de creencias que nos impone el papa u otro patriarca religioso, para escuchar lo que nos dice la Madre Tierra sobre el quehacer de las cosas. Desde la psicología andina realizamos ceremonias con lo sagrado y que no está metido dentro de los muros los templos, sino en toda la naturaleza y todos los seres de nuestra naturaleza.

La religión divide, no ve lo que se discute sobre sus dogmas, la gente se pelea, como lo generado en nuestro país por el tema del aborto. La espiritualidad une, hermana, nos hace completos. No visualizamos la vida como sufrimiento o como "valle de lágrimas", sino "fiesta sagrada" por la que agradecemos con nuestras ceremonias. La religión aprisiona, enferma, la espiritualidad libera, transforma, sana, las religiones son sistemas de creencias que no les interesa la profundidad de la espiritualidad, sino la sumisión. Estas formas dogmáticas de creencias, desean la sumisión del pensamiento: "Amén, así sea, mande usted, mi señor", para ocultar que la espiritualidad y nada tiene ver con jerarquías, dogmas, mandamientos, sacerdotes, profetas, textos de verdades reveladas y todo sistema externo impuesto para disciplina del cuerpo y del alma. La espiritualidad no está limitada por divisiones geográficas, históricas o sectarias; de esta manera, la dimensión sagrada espiritual del bioverso se vuelve teología y, por tanto, la espiritualidad se domestica y es atacada por una visión teo-céntrica, que se vuelve un instrumento de ejercicio de poder manipulado por quienes postulan la existencia de dicho centro, negando la existencia de otras espiritualidades, a las que se ha declarado la guerra y se las ha calificado de idolatrías, brujería, paganismo, y en nombre de un Dios blanco, masculino y castigador, se han cometido las más grandes barbaries en la historia humana.

Al respecto, nos dice la sabiduría de de nuestros abuelos: La espiritualidad no era una religión, según la definición comúnmente aceptada. Era su forma de vida, impregnaba la vida cotidiana. No había conceptos teístas, ni trascendentes.

Necesitamos aprender de nuevo a mirar para volver a descubrir las vibraciones, los sonidos y múltiples colores de la realidad de la vida sudamericana, poniéndonos aparte de la solemnidad de lo científico que nos fumigó la alegría de nuestro trabajo. Es casi una revolución del sentir para erradicar la actual civilización de la cultura de la muerte, de la violencia y de la crueldad. El efecto global debiera ser, según mi sentir y pensar de latinoamericana, lograr enlazar nuestras manos para hermanarnos, reconstruyendo el tejido de la alteridad y potenciando la fuerza colectiva, fuerza absolutamente debilitada actualmente, por efecto de un calentamiento global de nuestros afectos, que nos impiden llegar a ser personas entre todos, con otros y para otros. Nuestro tejido social comunitario está fracturado en mil pedazos, facilitado por la pandemia de niveles tóxicos de hiperdesarrollo narcisista, para la cual no hay 
vacuna posible, hasta que no alcancemos la conciencia clara de nuestro ser social, producto de otros y necesitado de otros, tal como lo entendían nuestros ancestros andinos originarios.

Entonces proponemos este movimiento de psicología andina para la liberación, hacia una dimensión comunitaria, que descentre a los contaminados por la "egofrenia" individualista en éxtasis narcisista, revirtiéndolo hacia una tarea con, para y por los otros, tal como lo insinuaba Pichón Rivière hace ya más de cinco décadas. Tal como hoy lo ejercitan todos los colegas enrolados en una psicología social comunitaria, dándole lugar de excelencia al ejercicio de la prevención. Esta movida a mi juicio es representativa de los que "en bandadas, van alimentando vuelos" de transformación social, tal como lo expresa claramente la colega Carolina Wajnerman en su publicación de arte popular y transformación social comunitaria, con una frescura y claridad especial, desarrollando un texto para volar y aterrizar en una América del Sur desde el arte y la política. Ella con su composición y canto pone de manifiesto la expresión adormecida de los andinos (Wajnerman, 2018).

Partimos de la base por fundar una psicología andina, comprometida con nuestra vida sudamericana, no como un nuevo reto discursivo de los conocimientos "ventrílocuos" que reproducen los centros hegemónicos del conocimiento y sus textos bibliografías. Proponemos una descolonización del saber que efectivice un hablar de la vida con nuestras palabras, evitando lenguajes jeroglíficos que transforman nuestra comunicación, inaccesibles para la gente común, a punto tal que da la impresión que pronto necesitaremos y GPS para comunicarnos.

Los andinos han callado por siglos, de tal forma que el antropólogo Adolfo Colombres lo describe como "una táctica del silencio indígena", porque el indio es el único a quien no se le reconocía el derecho a manifestarse (Colombres, 1996). Fue su forma de preservarse de despojos, vejaciones, torturas, ejecuciones y mutilaciones padecidas por más de cinco siglos, pasando del silencio, el destierro y el olvido. Nuestros ancestros andinos no hablaron más, pero dejaron sus mensajes milenarios en el aire, la música, las danzas, los ritos, las comidas, los silencios y sus miradas en-re-da-das de todos y para todos. El silencio andino es el de la prudencia, mecanismo de defensa con sus culturas avasalladas, ninguneadas y pisoteadas por el invasor español de la corona y el sistema papal de la religión católica.

El colombiano Carlos Arango, otro pensador psicoandino, destaca cómo en Sudamérica se ha venido padeciendo en las últimas cinco décadas una ola de violencia, cada día más creciente, singularizada por asesinatos de toda clase, desapariciones, secuestros, extorsiones y posteriormente sumándose otros componentes sociales como la delincuencia común, el narcotráfico y el terrorismo. Los índices de violencia superan en proporciones significativas a lo que pueda ocurrir en cualquier otro país que no se encuentre directamente comprometido en una guerra.

En estas circunstancias asegura algo con lo que coincido plenamente, que ha cobrado importancia y necesidad el hablar de paz y convivencia, pues sentimos todos que se ha quebrado el orden "natural" de los vínculos interpersonales y las relaciones 
sociales. Sobre todo en un continente donde tanto nos cuenta re-conocernos y continuamos siendo sujetos de colonización con cuanta teoría o técnica externa y ajena a lo nuestro se nos ofrezca en el mercado de las ideas.

El problema de la convivencia adquiere más importancia en la medida que el contexto de las luchas entre los que codician el poder, resalta la importancia de elaborar ideas de paz, para crear condiciones de resolver conflictos de forma pacífica, desapareciendo usos de todas las formas violentas, para la democratización de la sociedad y la construcción de sana convivencia.

Su "programa de convivencia" remite a las formas en que las personas se vinculan entre sí, desde lo personal, con niveles interpersonales más amplios, hasta lo vinculado con la vida y la naturaleza, totalidad más amplia, a la vez que remite a caracterizar la génesis y desarrollo de los vínculos sociales.

Entonces, agrega Arango desde esta perspectiva psicosocial y holística, se entiende a la psicología de la convivencia como el proceso de reconocimiento, elaboración, fortalecimiento y/o transformación de nuestros vínculos interpersonales. $\mathrm{La}$ construcción de un plan para el desarrollo, con fortalecimiento de la convivencia en el contexto de un barrio, no tendrá sentido sin el concurso y respaldo de todas las instituciones. Es el mejor resumen de la propuesta psicoandina para recuperar el entre todos, para alcanzar el para todos esperado.

He revisadola bibliografía pertinente delas formas de entender la salud, la enfermedad, la curación y la muerte para los andinos de antes y de hoy, con investigadores argentinos, salvadoreños, ecuatorianos, brasileños, bolivianos, peruanos y chilenos. Uno de mis maestros, Paulo Freire, después de haber escrito sus maravillosos textos sobre la pedagogía de la liberación, nos dejó su ultimo legado la pedagogía de la esperanza. Este texto ponía en evidencia sus deseos de un futuro diferente para la educación sudamericana, liberada de de la predeterminación europeizante. Pero Paulo ni en sus peores pesadillas se hubiese imaginado a Brasil bajo un gobierno fascista que propone destruir toda su obra educativa revolucionaria.

También me sumo a la ilusión de un futuro para nuestro continente, liberado de la opresión cultural colonizadora, con la recuperación de un INTI sobre las cumbres de nuestro amado Andes que nos integra y vincula por siempre y desde siempre.

Como nos decía Julio Cortázar (1962), los cronopios nunca mueren y ellos son los encargados de volver a subir a la palmera a la esperanza que se encontraba desaparecida. Seamos como los cronopios andinos y, nunca dejemos desaparecer la esperanza. 


\section{Referencias}

Arando Calad, C. (1995). Psicología comunitaria para la convivencia (Tesis doctoral inédita) Universidad de València, España.

Bianchetti, M. C. (1996). Cosmovisión sobrenatural de la locura. Salta: Hanne.

Bianchetti, M. C. (2017). Tras los rituales de Pachamama. Salta: Hanne.

Bleger, J. (1970). Psicohigiene y medicina. Buenos Aires: Horme.

Bugallo, L. y Vilca, M. (2018). Wak'as, diablos y muertos. Alteridades del mundo andino. Jujuy: FFYL UNC.

Colombres, A. (1996). La hora del bárbaro. Serie antropológica. Buenos Aires: Ediciones del Sol.

Cortázar, J. (1962). Historias de cronopios y de famas. Madrid: Alfaguara.

Cullen, C. (1986). Ser y estar. Dos horizontes para definir la cultura. Rosario: Ross.

Cusicanqui, S. (2015). Sociología de la imagen. Buenos Aires: Tinta Limón.

Cusicanqui, S. (2016). Una mirada sobre prácticas y discursos descolonizadores. Buenos Aires: Tinta Limón.

Cusicanqui, S. (2018). Un mundo ch'ixi es posible. Buenos Aires: Tinta Limón.

Dussel, E. (1988). Filosofía de la liberación. México, D.F.: Fondo de Cultura Económica.

Figueroa, L., Silva, K. y Vargas, P. (1990). Tierra indio y mujer. Pensamiento social de Gabriela Mistral. Santiago de Chile: Universidad Arcis.

Freire, P. (1992). Pedagogía de la esperanza. México, D.F.: Siglo XXI.

Guerrero Arias, P. (2004a). Corazonar. Quito FONDE.

Guerrero Arias, P. (2004b). Usurpación simbólica identidad y poder. La fiesta. Quito: ABYA-YALA.

Guerrero Arias, P. (2012). Descolonización desde las sabidurías insurgentes. Asunción: DIM.

Guerrero Arias, P. (2017). El trabajo antropológico. Quito: Universidad Politécnica.

Guerrero Guerrero, A. L. (2016). Filosofía indígena y derechos humanos. México, D.F.: UNM.

Kusch, R. (1961). El hedor de América. Córdoba: UNC.

Kusch, R. (2007). Obras completas. Rosario: Ross.
Maidana, O. (1997). Desde el silencio de mi pueblo. Salta: Mileno.

Martín Baró, I. (1990a). Problemas de psicología social en América Latina. El Salvador: UCA.

Martín Baró, I. (1990b). Psicologia social de la guerra. El Salvador: UCA.

Martín Baró, I. (2003). Poder, ideología y violencia. Madrid: Trotta.

Martín Baró, I. (2013). Sistema, grupo y poder. El Salvador: UCA.

Maturana, A. y Varela, F. (1994). El árbol del conocimiento. Santiago de Chile: Editorial Universitaria.

Menéndez, E. (1987). La alcoholización: un proceso olvidado... Patología, integración funcional o representación cultural. México, D.F.: Centro de Investigaciones y Estudios Superiores en Antropología Social.

Menéndez, E. (1998). Modelo médico hegemónico: reproducción técnica y cultural. Natura Medicatrix, 51, 17-22

Menéndez, E. (2000). Participación social, ¿para qué? Buenos Aires: Cúspide.

Mistral, G. (1962). Gabriela Mistral, rebelde. Magnifica. Buenos Aires: Losada.

Pichón Rivière, E. (1980). Teoría del vínculo. Buenos Aires: Paidós.

Restrepo, C. L. (1994). El derecho a la ternura. Bogotá: Arango.

Schlemenson, A. (2007). Remontar la crisis. Buenos Aires: Granica.

Strada, O. (2017). La amistad contra la violencia. Madrid: Circulo Rojo.

Torres, A. (2008). ¿Por qué callan si nacen gritando? Poder, accesibilidad y diferencias culturales en salud. Salta: Iruya.

Torres, A. (2016). Reinvención de lo comunitario. Hacia una ciencia domiciliada en America Latina. Buenos Aires: El Ágora.

Videla, M. (1994). Prevención comunitaria. Buenos Aires: Cinco.

Videla, M. (2010). Credo por la ternura en tiempos de violencia. Buenos Aires: Koyatun.

Wajnerman, C. (2018). Arte popular y transformación social comunitaria. Buenos Aires: Artes Escénicas. 